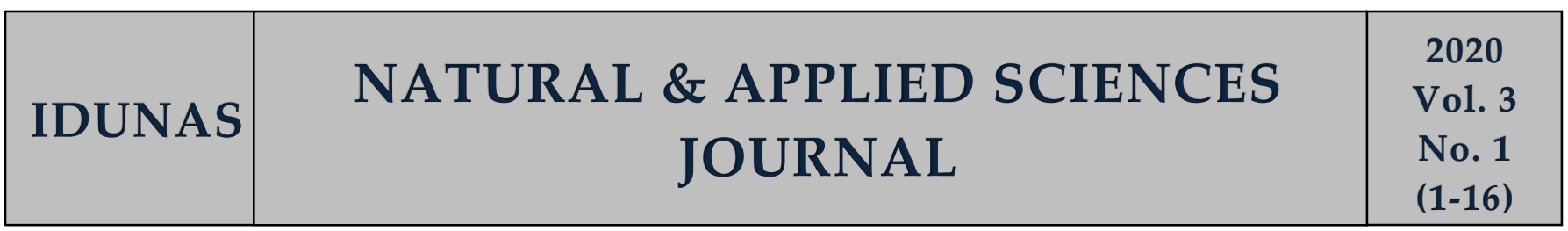

\title{
Role of Biomedical Engineering During COVID-19 Pandemic
}

\author{
Review Article

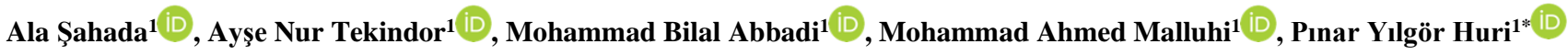 \\ ${ }^{1}$ Department of Biomedical Engineering, Faculty of Engineering, Ankara University, Ankara, Turkey \\ Author E-mails \\ phuri@ankara.edu.tr \\ *Correspondence to: P. Y1lgör Huri, Department of Biomedical Engineering, Faculty of Engineering, Ankara University, Ankara, \\ Turkey \\ Tel: +903126000100/ 1849 \\ DOI: $10.38061 /$ idunas. 754344
}

Received: June 18, 2020; Accepted: June 25, 2020

\section{Abstract}

In December 2019 the novel virus of corona-viruses family caused by SARS-COV-2 virus appeared in Wuhan, Hubei province, spreading rapidly throughout China, just a few weeks later it starts spreading all around the world bringing severe consequences that should be laid out and studied in order to raise the level of readiness to face the upcoming pandemics. This review paper aims to scheme out the social and the economic effects of Covid19 Pandemic, and the importance of the healthcare infrastructure in the response to the rapid spread of pandemics.In this paper the roles of 3D printing, artificial intelligence integrated in different technologies in the urgent response to pandemic like Covid-19 is reviewed. In addition, the very wide research area of vaccines and treatments are covered, reviewing the most promising candidate drugs and vaccines that entered the clinical trials to date. In coorperation with several other disciplines, biomedical engineering with its wide range of application areas played an important role in the propagation of the urgent response.

Keywords: Covid-19, SARS-COV-2, Economics Impacts, Social Impacts, Biomedical Engineering, Healthcare Infrastructure, 3D printing, Artificial Intelligence, Vaccines.

\section{INTRODUCTION}

Since the beginning of suspicions about the spread of a virus in China in late 2019, and its possibility of transmission between humans, people all over the world have started asking many questions about what is the nature of this virus? Is there a cure? What are the methods of prevention? How is life in quarantine? and many other questions. Unfortunately, at the moment of writing this article, deaths of this virus have reached (340 thousand) and (5.5M) infections around the world [1]. And as if we are watching a fantasy movie, the cities that have always been crowded and full of tourists, vendors and photographers, now sit empty and surrounded by a shadow of fear and anticipation as people remain indoors and avoid crowds during the coronavirus pandemic. 
Our goal in this report, despite the few - and rapidly changing - sources till this day, is to give an overview, but at the same time, a comprehensive overview of all the effects of Coronavirus, with a focus on the field of healthcare and medical devices. A historical background of the virus, its ways of spreading, and its social and economic impacts on societies will be introduced. Then we will talk about the health system infrastructure, medical devices and tools used to counter the spread of the virus. Finally, we will mention the methods that have been tested and accepted in its possibility of treating the virus.

\section{COVID-19}

In late December 2019, the WHO office in China received a report of a disease that can spread between humans, which was observed in early December in Wuhan, the capital of Central China's Hubei province. Because of the strange symptoms and the lack of knowledge of its causes, the doctors called it "pneumonia of unknown etiology." And by mid-January, the spread of this disease was proven in all provinces of China in addition to many other countries [2]. On Wednesday, March 11, 2020, WHO Director-General Tedros Adhanum Gebresus announced that the United Nations organization considered the new Coronavirus, which is spreading across the globe as a "Global Pandemic". Since that time, the number of cases of infection and morality increased rapidly all around the world, Figure 1 shows these numbers.

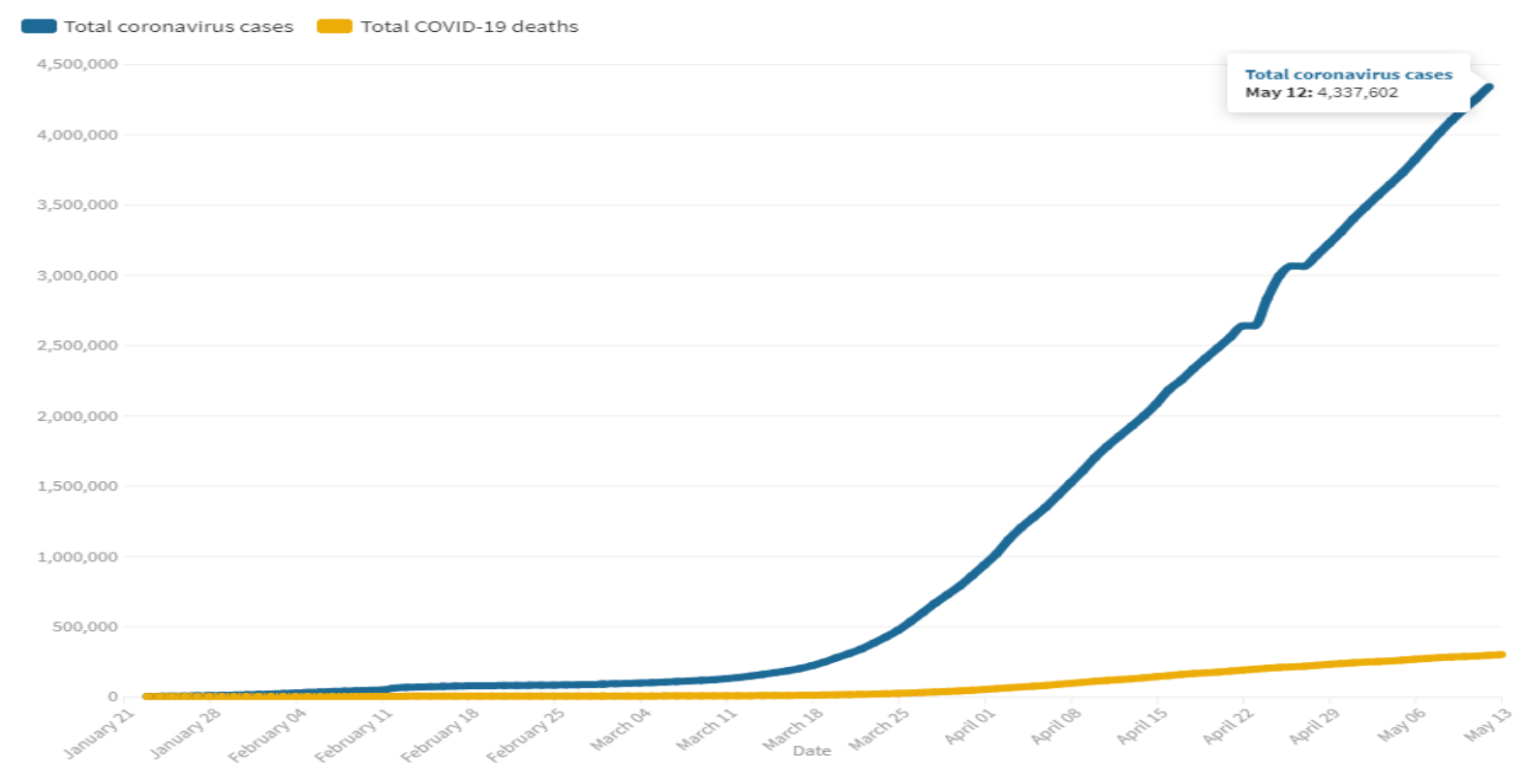

Figure 1. COVID-19 infection and deaths over time. *Euronews statistics.

Coronaviruses are a family of viruses discovered in the 1931s that infect mammals and birds. "The term coronavirus (Latin: corona, crown) was adopted for these agents, because of their characteristic fringed appearance under the electron microscope after negative staining" [3]. These types of viruses commonly cause mild (like common cold) to moderate upper respiratory tract illnesses. There are hundreds of types of coronaviruses that infect animals, such as cats, pigs, or bats. For many reasons and in different ways, these viruses can be transmitted to humans causing similar symptoms on the respiratory system. In the 1960s, first human coronaviruses were discovered [3]. According to the researchers' findings, the coronaviruses that can infect humans are:

- $\quad$ (229E, NL63, OC43 and HKU1); cause symptoms of the common cold.

- (MERS-CoV, SARS-CoV and SARS-CoV-2 or COVID-19); cause serious, even fatal, diseases. 
Furthermore, it was confirmed that SARS-CoV and MERS-CoV originated in bats, and since they are from the same family which leads to the possibility that SARS-CoV-2 also originated in bats [4].

\section{SOCIAL AND ECONOMIC IMPACTS}

Epidemics used to kill millions of people, including cholera, plague and measles [5]. Despite the advancement of medical technologies and healthcare systems, the 21 st century witnessed an outbreak of many infectious diseases that sparked panic around the world, including the Coronavirus, which is the last link in the series of epidemics that struck the world, killing millions of people. When the disease spreads between people and turns into a local epidemic then a pandemic, their effects are not only limited to human physical and psychological health, but also cause many crises, including economic, social, and lack of resources.

\section{Social Impacts}

Coronavirus's spread affected all groups of society, but there are groups who are more susceptible to this and other diseases than others. UN reports [6] indicate that: people living in poverty situations, older persons, persons with disabilities, youth, and indigenous peoples are the most vulnerable group that is affected by the social and economic impacts of the virus. The statistics indicate that a large percentage of deaths are from this category.

With the importance of the government's precautions to prevent the spreading of the virus, such as social distancing and the lockdowns, many news and resources point to a rise in domestic violence. After 4 months of the outbreak, The Secretary General António Guterres from the United Nations called on Twitter for urgent action to reduce domestic violence towards women; "I urge all governments to put women's safety first as they respond to the pandemic" [7]. It is true that people may be experiencing difficult times these days because of the news or fragile resources, and that any word may be a reason for a quarrel. But this remains in the normal state among families if it does not turn into violence. The Guardian newspaper, which published an article a while ago showing an increasing in the number of domestic violence in many countries. In Russia, reported cases of domestic violence have more than doubled during the country's coronavirus lockdown which started in the late of march. According to recent reports; "The UK's largest domestic abuse charity, Refuge, has reported a $700 \%$ increase in calls to its helpline in a single day, while a separate helpline for perpetrators of domestic abuse seeking help to change their behavior received $25 \%$ more calls after the start of the Covid-19 lockdown" [7].

\section{Economic Impacts}

Despite the importance of many precautions made by governments to reduce the spreading of disease, this has had a major impact on the country's economy and the living conditions of the population. Any decline in the economy, will only lead to a cessation of the circulation of money, which will also lead to a decrease in the money available for use in treating people and limiting the spread of the virus. If the spread of virus continues, there would be a contraction in the economy of developed countries by 5 percent. And the production of developing countries will be reduced at least by 0.7 percent. In addition, the pandemic will likely cause an estimated $\sim 34$ million people to fall below the extreme poverty line in 2020 , with more than half of this increase occurring in African countries. Also, Lockdowns, travel restrictions and the closing of national borders implemented by governments have caused a freezing in the economic activities across the board, wherefore "world trade is forecast to contract by nearly 15 per cent in 2020 amid sharply reduced global demand and disruptions in global supply chains" [6].

Therefore, it can be seen that the effects of this pandemic will not only hit the economic of poor or "developing" countries, the top economics in the world will be affected, for example, in China, where the outbreak of the virus first started, a drop by $13.5 \%$ of industrial production was shown, while the seasonally 
adjusted retail sales fell by $21 \%$. Also, different sectors have almost completely collapsed, for example, Car sales fell 92\%, and restaurant sales dropped by $\sim 95 \%$ [8].

\section{Tourism During the Pandemic}

One of the most severely affected sectors by the spread of the virus is the tourism sector, as the first step for most countries in limiting the spread of the virus was by closing borders and airports, in addition to closing all places and places that may cause gatherings between people. this of course has affected the workers, companies and projects in the tourism sector, and because of that, a loss of 100.8 million of related jobs is expected worldwide by 2020 (see Figure 2). Asia Pacific region is supposed to see the biggest loss from COVID-19, where a loss by 63.4 million of jobs is predicted, while Europe is the second hardest hit [9].

Assumptions about average daily expenditure and average length of stay of tourists were based on the Department of Tourism reports state that if the COVID-19 Pandemic lasts up to five months, the tourism industry of the Philippines will have an estimated earnings loss of about 170.5P billion (apx. 3 billion US dollar) [10]. Reem Al-Aseel, one like many small business owners, in Oakland, a city on the eastside of California, who was forced like other bakery and restaurant owners who were prevented from taking anyone inside, and they had to work for only limited hours, and reduce the number of their employers. As Assil puts it, "The money is running out, and there's no sight of the money coming in." [11]

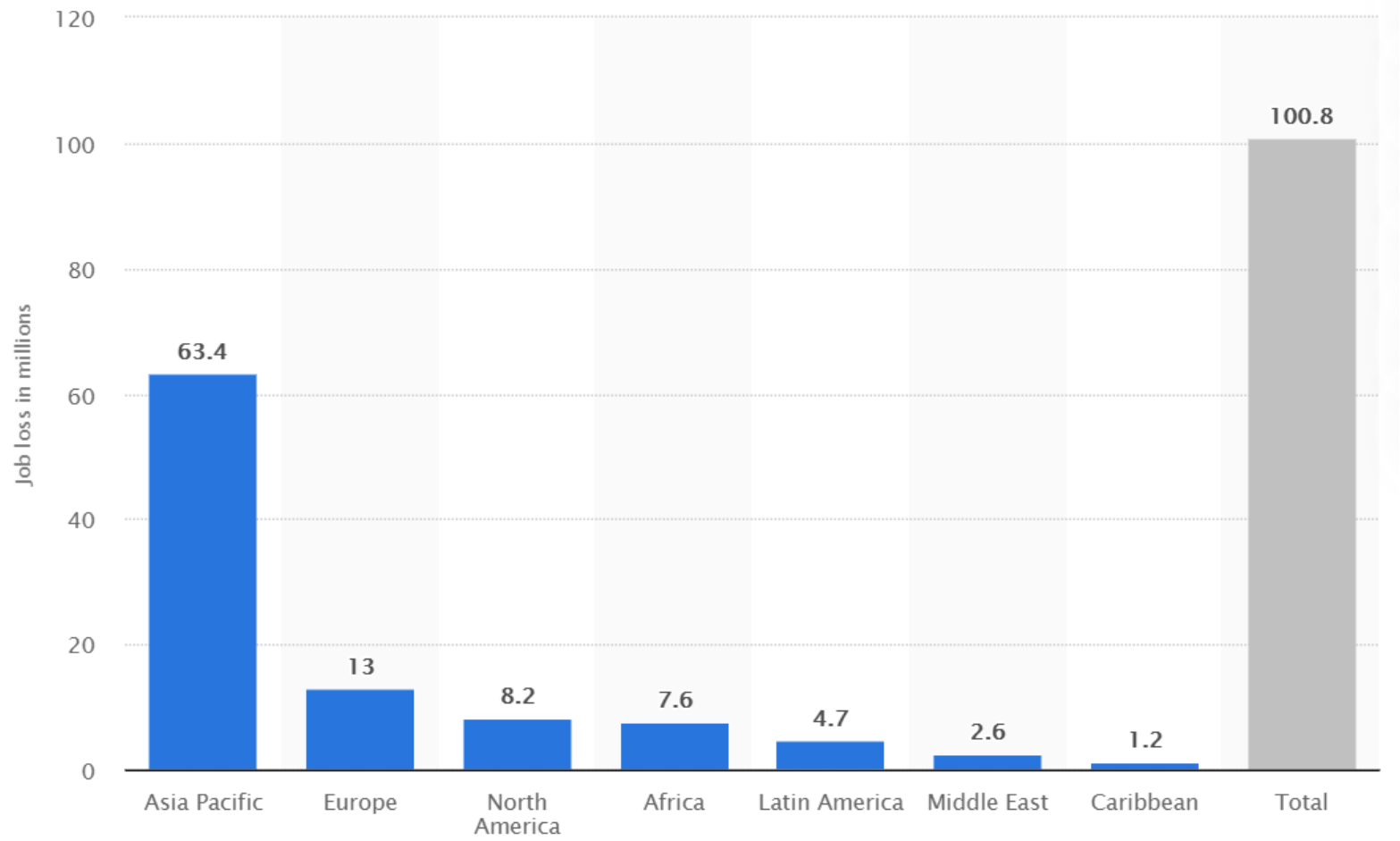

Figure 2. Predicted employment loss in the travel and tourism industry due to the coronavirus (COVID-19) pandemic worldwide in 2020, by region (in millions) [9].

\section{Healthcare Infrastructure}

The methods of dealing with the Coronavirus crisis varied from countries to countries on a large scale. Some governments have resorted to restricting all unnecessary internal moves. And not only is the move from one city to another, but the movement has stopped within the major cities around the world with the application of restrictions on the movements of citizens and communication within society. A curfew has been imposed for certain days or stings of the day, with the suspension of schools and some places that 
may cause the transmission of the virus, such as restaurants, cafes and cinemas. Table 1 summarizes the most used different public health measures [12].

Table 1: Non-Pharmaceutical public health interventions to control disease outbreaks, adapted from Cetron and Simone [12]

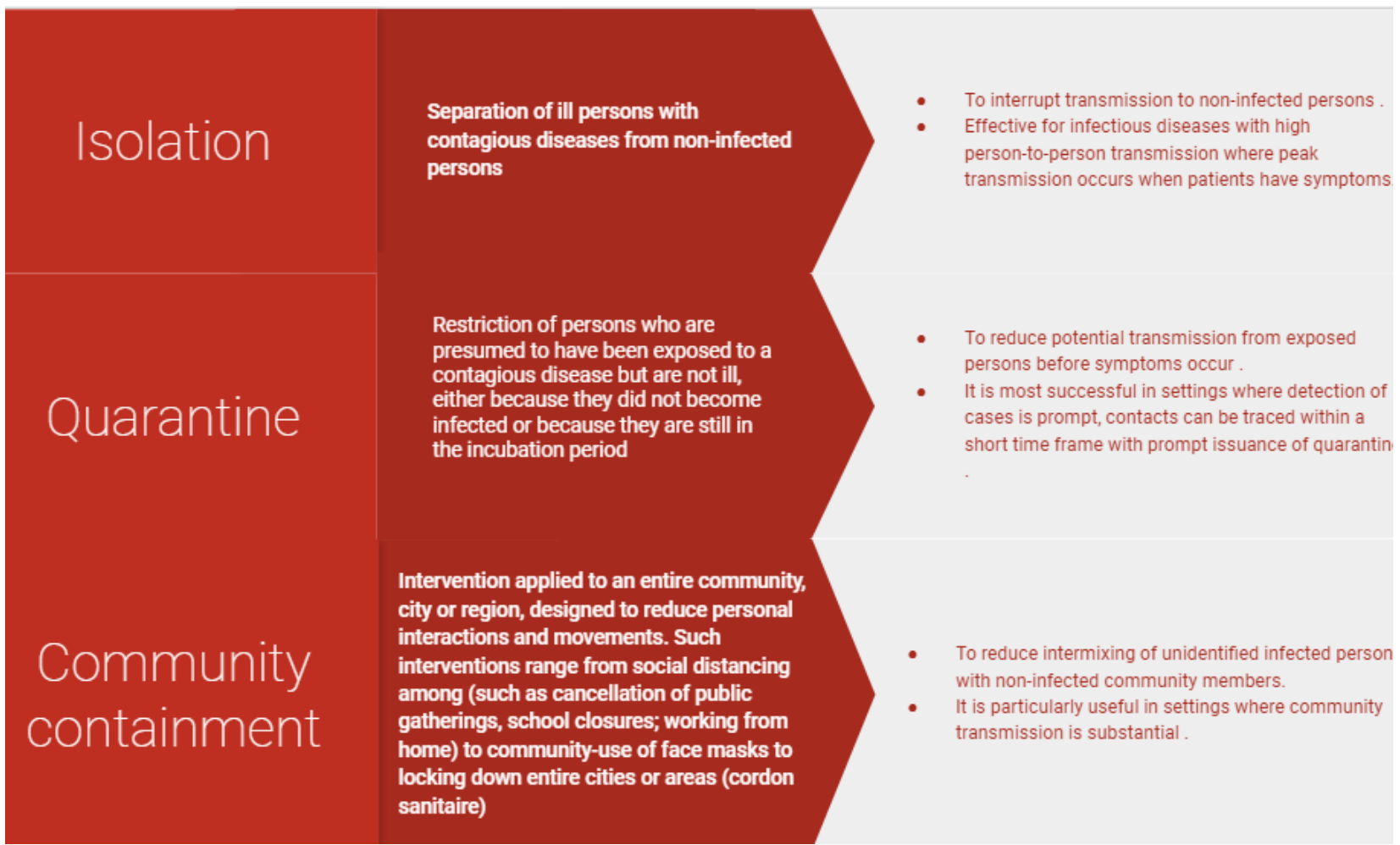

On the other hand, the responses and precautions of some countries differ to limit the spread of the Corona virus and treat patients with it, depending on the infrastructure and health systems of these countries. After the outbreak in China, then the European countries became a focus of the spread of the disease, and this has many reasons that will not be addressed in this report, but it can be summarized in the dependence of these countries on tourism and trade with other countries, which may be the reason that helped spread the virus significantly there. However, it can be noted that the European Union - although some countries have not implemented it - has a plan to confront the outbreak of any global pandemic that may threaten the public health, which can be considered to be followed in most countries and even non-Europeans, Figure 3 , that is summarized in the definition of risk first, then planning and training with cooperation between all sectors [13]. 


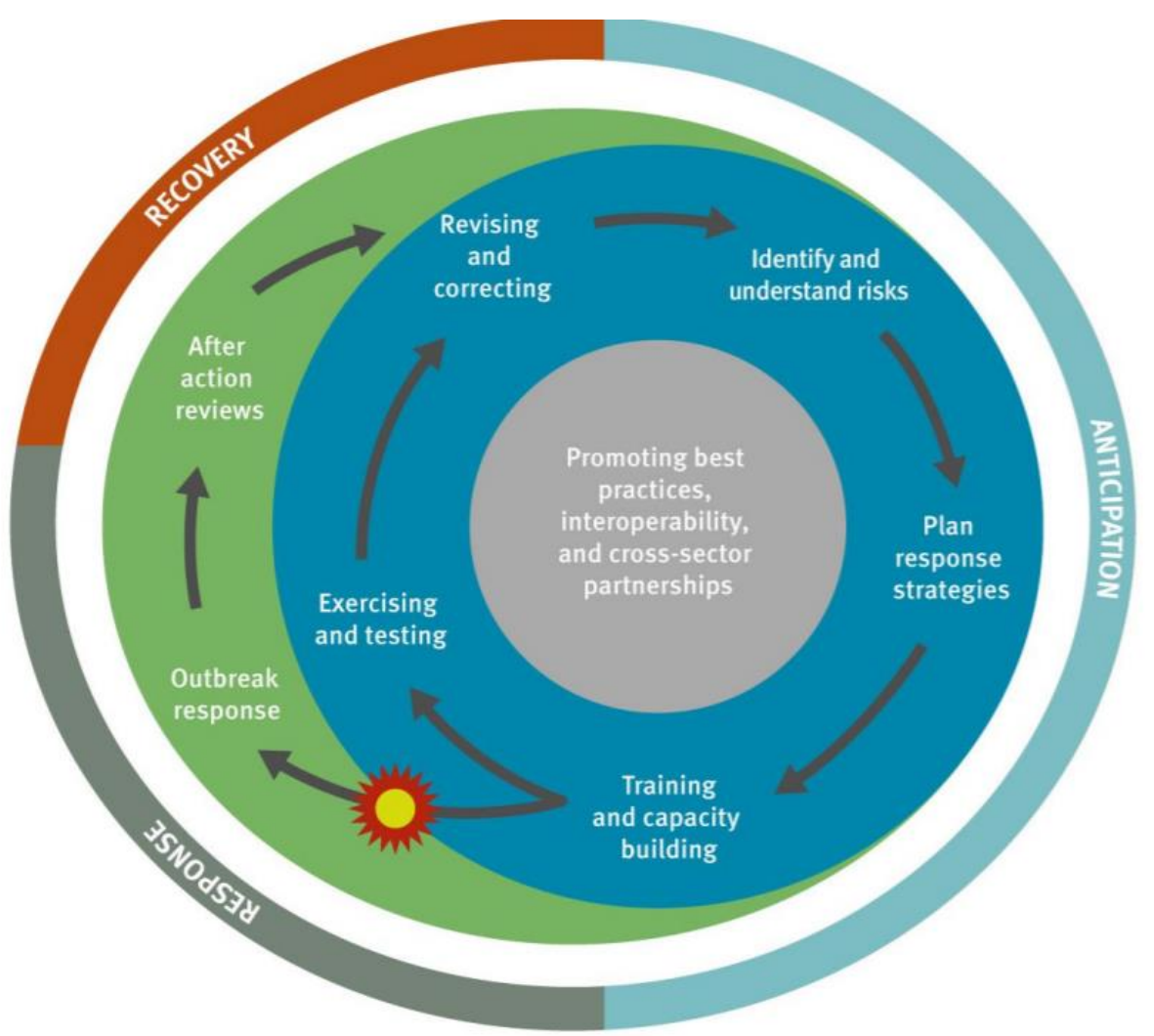

Figure 3. The preparedness cycle for pandemic s of high consequence infectious diseases (HCID).

\section{BIOMEDICAL DEVICES AND TECHNOLOGIES DURING COVID-19 PANDEMIC}

In diagnosis and treatment of Covid-19 disease, a number of medical equipment and devices are needed and the success on handling this pandemic is proportional to the availability of these medical equipment and devices. Personal Protective Equipment (PPE) including respirators, surgical masks, gowns, gloves, face shields, Diagnostic tests and test devices, Intensive Care Unit equipments such as beds, ventilators, and Medical diagnostic devices like Computed Tomography (CT), ultrasound device can be referred as needed medical device and equipment for fighting Covid-19.

Safe working area is provided for health workers with enough PPE. When it is provided, the number of infected health workers can be kept under control. Also, in order to reduce the number of entrances to a patient's room, catheters should be implemented when the patient comes to the intensive care unit [14]. Patient monitoring is another important point during treatment. Information such as side effects of the used medications and general situation of the patients is provided by monitoring.

While the Coronavirus most affected symptom is seen in the lungs, causing a failure in the breathing process, the ventilators are able to take over it. This gives the patient time to fight off the infection and recover. Difficulty in breathing is seen on $19 \%$ of Covid-19 patients. According to the latest data, for 5\%- 
$14 \%$ of patients, non-invasive mechanical ventilation; for $2 \%-12 \%$ of patients, invasive mechanical ventilation is applied [15-17].

Showing lungs in a radiological way has a great importance. Due to the limited number of application centers and false negative results of Real-Time Polymerase Chain Reaction (RT-PCR) test, radiological imaging is used. Chest X-Ray, CT, and ultrasound are applied. CT shows focal ground-glass opacity and multifocal lung opacity in early stage (2-4 days). Then, during the middle stage (5-13 days) an increasing lung consolidation and higher rates of bilateral and multilobar involvement was shown. Latestage CT findings (14 days or longer) showed varying degrees of clearing but no resolution up to at least 26 days [18]. According to the studies, sensitivity of RT-PCR test is $71 \%$ and sensitivity of CT is $98 \%$ in early stage of the disease [19]. Ultrasound can be used as a tool to identify Covid-19 findings such as tracking pneumonic infiltration and thickening and/or irregularities in the pleural line [20].

\section{Role of 3D Printing Community}

The number of medical devices like PPE and ventilator may not be sufficient while fighting Coronavirus and they have vital importance. A number of countries have stated their need for these devices for prevention of the disease and treatment. As demand exceeds available supplies of these devices, the supply chain is stressed. With increased number of Covid-19 cases, increased use may exceed the available supply of PPE, that results in a shortage at healthcare organizations [22]. It is aimed to combat Covid-19, and respond to the need for personal protection with 3D printer technologies. Across the globe, specialists, engineers, and designers have already begun to respond to the global crisis in order to support the manufacturing of PPE and other medical devices [23]. And also, there are calls for volunteer work where anyone who is enthusiastic to support can join the community.

Besides manufacturing masks and face shields, there have started different approaches for developing solutions to ventilator shortage problems. Multiple patients treatment with one ventilator is an important development. In the United States, a team of engineers at Johns Hopkins University was able to develop and prototype 3D printed ventilator splitter [24]. Moreover, in Italy, hospitals have run out of respiratory valves, and the original supplier was not able to meet the sudden high demand. Which was an opportunity for an engineering firm to manufacture these valves by $3 \mathrm{D}$ printing with an affordable price [23]. According to the demands, a 3D-printed respiratory device can be produced as a prototype in order to meet the need [25]. In addition, 3D- printed nasal swabs are in use to support Covid-19 tests [26].

3D- printed tools and components can be used instead of original components in a short time. While bringing benefit, these designs could bring risk as well. Quality, safety, and efficacy of these designs cannot be ensured unless proper quality controls and processes are done during and after manufacturing. 


\section{Artificial Intelligence Applications During the COVID-19 Pandemic}

Artificial intelligence- based technologies help healthcare organizations handle viruses and fight them back. It may be used to identify potential upcoming pandemics or epidemics in earlier stages before they spread. Through analyzing data, prediction and tracking of patients is possible. It may also be used for more proper understanding of despises as well as developing and testing new vaccines.

- $\quad$ Early detection and diagnosis of the infection:

Artificial intelligence can be used for analyzing people's data, their internet-searching subjects for identifying and detecting irregular symptoms and how frequent they are which may be very effectively helpful in the decision-making process and thus providing a faster response to epidemics.

AI technology can also help in developing new and more global diagnosis and management systems for the epidemics. This can be through in creating new faster ways for diagnosis of cases [27].

- $\quad$ Monitoring the treatment and the global cases distribution:

AI can be used in analyzing the day-to day cases around the world for predict the future spreading behavior of the epidemic in order to acquire a better preparation and response which can be life-saver as well as lower costing [27]

- One great application of AI is the tracing of individuals with viruses and monitoring them which can help in identifying the circle of people that they might have infected. This can be used in minimizing the spreading of virus to a wider range of people and thus help in controlling and eliminating the disease. An example of that is Apple-Google's joint effort for notification people via mobile phones. When a person contacts someone with coronavirus, the program will notify him that someone whom he was in contact with has tested positive to the virus [28].

- Also, AI is used for drug delivery design and development for vaccines. Ai can spot patterns in data, analyze the structure of viruses, compare with previous cases, identify some possible drug prospects to be tested on humans in months which would take years in a normal way. For that to happen, a huge amount of information and researches should be obtained. Using AI allowed researchers to see and identify patterns in data that they couldn't see with the ability to analyze lots of compounds in very short time [29].

- $\quad$ Reducing the workload on healthcare facilities and workers during pandemics which is caused by huge numbers of patients in a short time. AI based tests can make the process of testing and diagnosing of infection in patients easier and more efficient [31]. One example is an AI-based automated CT image analysis tool for detection of coronavirus infection in patients. The system uses some previous machine learning models that were then modified for this purpose with the use of Multiple international datasets as material for the system. They said the system was able to differentiate coronavirus patients from nonpatients [30].

\section{VACCINE DEVELOPMENT}

By May.2020 several hundreds of companies and research entities are working on developing about 115 candidate vaccines, 271 potential therapy for covid-19. 


\section{Vaccines in Clinical Trials Phase}

Vaccines are made against specific functional part of the virus inactivating the virus, COVID19 disease is caused by SARS-COV-2 virus, this virus has a spherical structure, on this structure a spikes of different proteins are located, $\mathrm{S}$ protein is one of those proteins that binds to the ACE2 receptors in the cell allowing the diffusion into the intracellular environment.

The immunological response for SARS-COV-2 virus starts by recognising the virus by the antigen presenting cell called macrophages, macrophages will devour the virus breaking it down into small pieces, the $\mathrm{S}$ protein that covers the surface of the virus will be presented on the mhcII molecules stimulating the T cells that will leads to activating the B cells that has the receptors of S protein which is lymphocytes, B cells then copy itself and turn into a plasmid releasing antibodies.

The response of the immune system for SARS-COV-2 is not immediate and may takes around one to two weeks, during this time the proliferation of the virus may causes death or sever statues, the vaccine role is to introduce the antigen with non harmful way, then by activating B cells that save a copy of the antigen, quicker response will occur when the real virus attacks.

However, the virus will dispersal around the world and by moving around nations will be exposed to genomic mutation, the vaccine designed should keep effective till with mutated virus [32].

There are different types of vaccines under research, below is a quick review for the ones that entered the clinical trials stage:

\section{DNA Based Vaccines:}

\section{- DNA plasmid; INO-4800}

DNA plasmid is a double strand DNA (normally taken from bacteria) that has the property of being programmable by computer sequencing technology, DNA plasmid is used to deliver an optimised DNA into the cell to induce specific immunological response generating a robust targeted $\mathrm{T}$ cells and antibody responses, for this candidate vaccine a device called CELLECTRA® 2000 used to provide and electrical pulse that allow the cells to open reversely allowing the plasmid to enter the cells. [33] [34]

Inovio Pharmaceuticals started the preclinical research by January 2020 conducting the in vivo and in vitro primary research, the clinical trials on the INO-4800 potential vaccine started by April 2020, and expected to get the initial result by June 2020 to proceed to the phase 2/3 by summer 2020 [33].

A DNA plasmid based vaccine is promising due to being cheap, safe, and big quantities can be manufactured easily which will help deliver the vaccines if they succeed for as many people as possible [35].

\section{mRNA Based Vaccines}

mRNA is a single strand molecule that transfers the DNA instruction in the nucleus to the ribosome where the proteins which are doing different functions are translated.

mRNA based vaccines can be used to induce the immunological response in the cell, by using the host cells' transcription pathway.

\section{- $\quad 3$ LNP-mRNA (RNA; mRNA; BNT162)}

Researchers genetically synthesized an mRNA sequence based on the genetic information of (S) protein (that cover the majority surface of the virus[38]) SARS-COV-2, the mRNA sequence was encapsulated within a lipid nano-particle to help fusion into the cell, once the mRNA sequence is delivered into the cell 
the sequence will translate the order of producing $(\mathrm{S})$ protein on the cell surface which will induce the production of antibodies and therefore strengthen the immunological response of the cell. [38][37]

A collaboration between BioNTech, Fosun Pharma and Pfizer is working on developing 4 versions of mRNA vaccines some of them are in the clinical trials in phase I and other in clinical trials II, the initial data is expected by the end of June 2020. [36]

- $\quad$ LNP-encapsulated mRNA (mRNA 1273)

Another version of mRNA vaccine developed by synthesizing the mRNA from the genomic material of the virus's S protein gen, the synthesized will be delivered by a lipid nanoparticle into the body where it will diffuse into the cell, and the mRNA is translated into $\mathrm{S}$ proteins, the antigen of $\mathrm{S}$ proteins are recognized by the immune system inducing the production of antibodies and saving the antigen in the B cells allowing quicker response for the virus attack [38].

Research is conducted by a collaboration between three companies Moderna, NIAID and Lonza, and recently they announced the success of the phase I of the clinical trials done on 8 persons, they will proceed to phase II as they got the approval of FDA [36].

\section{Inactivated Virus Based Vaccines}

In this type of vaccines the virus is inactivated by a denaturing it using a chemical or physical factors, after the virus loses its ability of making any damage to the human body it is injected into the human body so the immune system get trained by responding for an inactive virus, and when the real virus attack best immunological response can be presented.

There are three inactivated virus based vaccines currently studied in the clinical trials.

- The Chinese biopharmaceutical in a collaboration with a company works on developing Inactivated virus based vaccines called (Picovacc) that proved efficacy in macaques, currently Picovacc is in phase $1 / 2$ of clinical trials. [36]

- Sinopharm Group (Wuhan Institute of Biological Products) and Chinese Academy of Sciences (Wuhan Institute of Virology) are working on an inactivated virus based vaccine, they got the approval of the China's National Medical Products Administration for phase I and phase II of their candidate drug. [39]

- $\quad$ Sinopharm Group (China National Biotech Group, Beijing Institute of Biological Products) in collaboration with the Chinese Center for Disease Control and Prevention are working on another inactivated virus based vaccine, and they were able to get the consent for the clinical trials from the China's National Medical Products Administration for phase I of clinical trials. [40]

\section{Non Replicating Viral Vector Based Vaccines}

- Adenovirus Type 5 Vector (Ad5-nCoV)

For this vaccine, a recombination of novel coronavirus disease vaccine incorporating the Adenovirus Type 5 Vector (Ad5-nCoV), taking the gene of the $\mathrm{S}$ protein and inject it into the adenovirus, then injecting the adenovirus into the human body allowing it to replicate and develop an immunological response against the $S$ protein so when the real virus activated virus attack better response of the immune system will be achieved [41]. 
CanSino collaborating with "China's Beijing Institute of Biotechnology and Academy of Military Medical Sciences", are working on developing this vaccine, and by April 12 Phase II clinical has been Launched [42].

\section{- ChAdOx1}

Oxford University with a collaboration with Jenner Institute is working on a vaccine called ChAdOx1 which is currently in phase I, the idea of the vaccine is to take the adenovirus from the chimpanzee that do not harm human being and treat it so it no longer has any harmful effect, then inserting the gene of the $\mathrm{S}$ protein in it, then injecting the vaccine in the body, when $\mathrm{S}$ protein is formed inside the body in safe way, the macrophages recognize it inducing the immune system to empower its own protection mechanism against the real virus when attacks.

Recently in 18 May the failure of this vaccine was announced due to its inability to resist the virus in animals.

\section{Treatments in the Clinical Trials Phase Corticosteroids}

Corticosteroids is a repurposed drug approved by FDA since the 1950s to treat many diseases, including anti-inflammatory conditions and some cancers [36], currently in the phase III clinical trials [43].

In February 2020 a study told that no evidence support clinical treatment of SARS-COV and MERS$\mathrm{COV}$ viruses by corticosteroid and referred to that it reduced the rate inflammatory response that may damage our body by the over functioning of immune system but delayed the clearance of the virus and caused complications during and after the disease such as diabetes, psychosis, avascular necrosis in survivors, Increased mortality expecting that that it will not benefit in treating SARS-COV-2 virus[44].

However a study conducted on 70 patients with COVID-19 severe pneumonia in France between 10 March and 9 April, 202 shew that a risk difference of $-47.1 \%$ (95\% confidence interval $-71.8 \%$ to $22.5 \%$ ) lowered the risk of intubation by corticotherapy, and it expected that this can be an important tool in managing severe Covid-19 patients suffer from respiratory failure [45].

\section{Remdesivir}

Remdesivir (RDV) is another potential treatment under repurposing research, previously was used as treatment for EBOLA, but still does not have the FDA approval. This research is in the phase III of clinical trials, and runs through a collaboration of three pharmaceutical entities, GLIAD, NIAD, and Feinstein Institutes. [36]

Study has been conducted on RDV efficacy on MERS-COV explained how RDV can be an effective treatment candidate against SARS-COV-2, the mechanism of action is that after the virus bind to ACE II receptor and fuse into the cell, the virus RNA is translated into different proteins one of them is RDRP, this protein the reverse transcription to the mRNA increasing the load of the virus, RDV works by mimicking the nucleotide base of Uracil (U) that places on the virus complementary mRNA preventing the right replication of the virus RNA, leading to reduction in both virus load and damage to the immunological response by reducing inflammation [46].

Another recent study showed that RDV enhances the recovery and accelerates the discharge of COVID19 patients, lowering the length of stay of hospitalization by a half, and reducing the death from COVID19 by $29 \%$ compared with those of the same severity rate with no RDV treatment [47]. 


\section{Chloroquine and Hydroxychloroquine}

Chloroquine and Hydroxychloroquine are antimalarial drugs that are under repurposing research for using for Covid19 patients, those two treatments has been issued by FDA for the emergency use by 28 march 2020, where there are over 50 clinical trials registered at clinical trials.gov [36].

The main property of these candidate treatments is their weak basic nature, knowing that the intracellular is an acidic environment, and the different enzymes function inside the cell need this acidic environment we can expect the role of those treatments. Decreasing the acidity of the intracellular environment of the cell will decrease the virus ability to diffuse into the cell, and the part which may be diffused will be so difficult to reassemble and replicate due to the need of the less efficiency of the intracellular machinery in basic environment.

Another benefit aspect of the hydroxychloroquine is being Zinc ionophore, meaning it help forming a channels to move the $\mathrm{Zn++}$ through the cells membrane as by nature the cell membrane is not permeable to $\mathrm{Zn++}$, the importance of the $\mathrm{Zn++}$ is that it disables the function of RNA dependent RNA polymerise needed for the replication of the virus inside the cell.

Hydroxychloroquine decreases the efficacy of the SARS-COV-2 receptors (ACE II) by preventing or reducing the glycation needed for the last amino acid of it during receptor building in the cell.

There are tons of studies that prove the efficacy of the inefficacy of the hydroxychloroquine that need special work to collect and summarize, however most of them are conducted on a small group of patients, and the results achieved depend basically on the patient profile and the administration way.

\section{Favipiravir}

Favipiravir is an antiviral drug licence in Japan to treat influenza, clinical trials on repurposing this treatment is conduction in Japan (phase III), USA(II) and India phase (III) with an expected results by July/ august [36].

Favipiravir function by inhibiting the RNA polymerase of RNA virus, blocking the replication of the virus [48].

\section{Effects of Vitamins and Minerals Vitamin C}

Vitamin $\mathrm{C}$ has an antioxidant property that is important for neutralizing reactive oxygen species, Vitamin $\mathrm{C}$ is needed for $\mathrm{H} 2 \mathrm{O} 2$ formation in the immunological cells to respond properly during.

China is conducting a clinical trials on the effect of the IV administered over dose of vitamin $\mathrm{C}$ for the treatment of sever Covid19 patients [49].

\section{Vitamin D}

Vitamin D is essential not for treating or inhibiting the virus but to keep the immune system works better, vitamin $\mathrm{D}$ has a role is suppressing the innate immune response and balancing the proinflammatory acquired immune response by modulate the releasing the Cathelicidin, Beta defensin and NFKB [50].

Recent studies showed that vitamin D deficiency is a reason for $\mathrm{C}$ reactive protein $(\mathrm{CRP})$ increasing rate, "CRP is an acute-phase protein binds to the dead or dying cells in order to activate the complement system" [51], Increasing the CRP rate will decreases the innate immune response which will rise the viral load and cause the severe immune response which may demand the patient to enter the ICU [52]. 


\section{Zinc}

Recent study has been mentioned that using the Zinc with hydroxychloroquine would affect the people discharge home number and would not effective on the length people being in ICU or get ventilated, Zinc play in important role in decreasing the replication rate of the virus RNA when it delivered to inside the cell by hydroxychloroquine [53].

\section{CONCLUSION AND FUTURE PERSPECTIVES}

Our world is currently facing the greatest challenges at all levels in the century; the novel Coronavirus, as these challenges were not limited to health problems only, but also to social life, the economy, unemployment rates, tourism and many others. Very few countries and places have relatively succeeded in confronting this disease and limiting its spread by taking the necessary measures and the effective use of resources. But, on the other side, the outbreak of this disease began very quickly, which did not allow many other countries to confront its consequences, as the shortage of medical devices and personal protective equipment puts many people, especially doctors and health workers, in inevitable danger. However, compared to the previous epidemics that humankind has undergone, there is no doubt that the development and technology has great impact in containing this disease, such as the use of 3D printing in the manufacture of ventilators and personal protective equipments, in addition to the use of artificial intelligence in the diagnosis and follow-up of patients to treat them, monitor their health and narrow the circle of infection.

Till now, there have been many advances in the development of a cure or vaccine for this virus. Some have been shown to be effective such as corticotherapy, RDV, Chloroquine, Hydroxychloroquine and Favipiravir, which are still in different phases of clinical trials, and/or issued for emergency use only. However, what is frightening in the new Corona, despite the research that has been carried out, is that researchers are unable to understand the mechanism by which the disease is transmitted from animal to human and thus weak ability to control it. Not to mention the high prevalence among people, the high mortality rate among critical groups and the lack of completely curative treatment so far.

Although we cannot predict precisely what days hide for us, we believe that this cloud will disappear one day, by our awareness, our unity, and by following health measures; we can triumph over this disease with the least possible losses.

\section{REFERENCES}

1. Lock, S. (2020, May 12). Loss in global tourism jobs due to COVID-19 by region 2020. Retrieved May 25, 2020, from https://www.who.int/

2. Cascella M, Rajnik M, Cuomo A, et al. Features, Evaluation and Treatment Coronavirus (COVID-19) [Updated 2020 Apr 6]. In: StatPearls [Internet]. Treasure Island (FL): StatPearls Publishing; 2020 Jan-.

3. Greenwood, D., Barer, M., Slack, R., \& Irving, W. L. (2012). Medical microbiology a guide to microbial infections: pathogenesis, immunity, laboratory diagnosis and control. Edinburgh: Churchill Livingstone Elsevier.Accessed May 23, 2020

4. NIH (National Institute of Allergy and Infectious Diseases) https://www.niaid.nih.gov/

5. Al Jazeera. (2020, March 10). A إلى فيروس كورونا. 10 أوبئة غيرت مجرى التاريخ البشري. Retrieved from https://www.aljazeera.net/news. 
6. United Nations, World Economic Situation and Prospects (WESP) mid-year update Report. Accessed May 05, 2020

7. Taub, Amanda. "A new Covid-19 crisis: Domestic abuse rises worldwide." New York Times 6 (2020). Accessed May 23, 2020

8. McKee, M., Stuckler, D. If the world fails to protect the economy, COVID-19 will damage health not just now but also in the future. Nat Med 26, 640-642 https://doi.org/10.1038/s41591-020-0863-y

(2020).

9. Lock, S. (2020, May 12). Loss in global tourism jobs due to COVID-19 by region 2020 . Retrieved May 25, 2020, from https://www.statista.com/statistics/1104835/corona virus-travel-tourism-employment-loss/

10. Centeno, R. S., \& Marquez, J. P. (2020). How much did the Tourism Industry Lost? Estimating Earning Loss of Tourism in the Philippines. arXiv preprint arXiv:2004.09952.

11. L. F. Emison (2020)" A San Francisco Baker on What Hospitality Looks Like During the Coronavirus Pandemic", The Newyorker https://www.newyorker.com/contributors/linneafeldman-emison Accessed May 25, 2020

12. A Wilder-Smith, MD, D O Freedman, MD, Isolation, quarantine, social distancing and community containment: pivotal role for old-style public health measures in the novel coronavirus (2019-nCoV) outbreak, Journal of Travel Medicine, Volume 27, Issue 2, March 2020, taaa020, https://doi.org/10.1093/jtm/taaa020

13. European Centre for Disease Prevention and Control. Health emergency preparedness for imported cases of high-consequence infectious diseases. Stockholm: ECDC; 2019.Accessed May 25,2020

14. Hancı, P.: COVID-19'un Yoğun Bakım Ünitesinde Yönetimi, Eurasian Journal of Pulmonology, 2019.
15. Guan WJ, Ni ZY, Hu Y, Liang WH, Ou CQ, He JX, et al. Clinical characteristics of coronavirus disease 2019 in China. N Engl J Med. 2020 Feb 28.

16. Wang $\mathrm{D}, \mathrm{Hu} \mathrm{B}, \mathrm{Hu} \mathrm{C}$, et al. Clinical characteristics of 138 hospitalized patients with 2019 novel coronavirus-infected pneumonia in Wuhan, China. JAMA. Published online February 7, 2020.

17. Zhou F, Yu T, Du R, et al. Clinical course and risk factors for mortality of adult inpatients with COVID-19 in Wuhan, China: a retrospective cohort study. Lancet. 2020;395(10229):1054-1062.

18. Kanne JP, Little BP, Chung JH, Elicker BM, Ketai LH. Essentials for Radiologists on COVID19: An Update-Radiology Scientific Expert Panel. Radiology 2020; 200527 (published online ahead of print, 2020 Feb 27).

19. Ceylan, N., Savaş, R., COVID-19'un Radyolojik Bulguları, Eurasian Journal of Pulmonology, 2019.

20. https://www.philips.com.tr/healthcare/medicalspecialties/covid-

19/ultrasound\#!=\&triggername $=$ menu_one [accessed 13.05.2020]

21. FDA.gov, FAQs on shortages of surgical masks and gowns

22. https://www.fda.gov/medicaldevices/personal-protective-equipment-infectioncontrol/faqs-shortages-surgical-masks-and-gownsduring-covid-19-pandemic [ accessed 23.05.2020]

23. M. Petch, 3D printing community responds to COVID-19 and coronavirus resources https://3dprintingindustry.com/news/3d-printingcommunity-responds-to-covid-19-andcoronavirus-resources-169143/ 24.05.2020]

[accessed

24. C. Graham. Johns Hopkins engineers develop 3D-printed ventilator splitters https://hub.jhu.edu/2020/04/02/3d-printed- 
ventilator-splitters-for-covid-19/ 24.05.2020]

25. Medically approved emergency $3 \mathrm{D}$ printed ventilator goes into production, https://www.3dnatives.com/en/3d-printedrespirator-230320205/[accessed 23.05.2020]

26. https://formlabs.com/covid-19response/covid-test-swabs/ [accessed 23.05.2020]

27. Raju Vaishya, Mohd Javaid, Ibrahim Haleem Khan, Abid Haleem, Artificial Intelligence (AI) applications for COVID-19 pandemic, Diabetes \& Metabolic Syndrome: Clinical Research \& Reviews, Volume 14, Issue 4, 2020, Pages 337339 , ISSN $1871-$ 4021,https://doi.org/10.1016/j.dsx.2020.04.012.

28. Fried, I. (2020, April 10). Apple, Google team up on coronavirus contact tracing. Retrieved from https://www.axios.com/apple-google-teamup-on-coronavirus-contact-tracing-6579b80f-f3484c8e-ac87-d823b9abb4fb.html

29. Commentary, G. (2020, March 17). The Role of AI in the Race for a Coronavirus Vaccine. Retrieved from https://www.informationweek.com/big-data/aimachine-learning/the-role-of-ai-in-the-race-for-acoronavirus-vaccine/a/d-id/1337278

30. Ophir Gozes, Maayan Frid-Adar, Hayit Greenspan, Patrick D. Browning, Huangqi Zhang, Wenbin Ji, Adam Bernheim, Eliot Siegel Rapid. AI Development Cycle for the Coronavirus (COVID19) Pandemic: Initial Results for Automated Detection \& Patient Monitoring using Deep Learning CT Image Analysis.

31. Marr, B. (2020, April 21). Coronavirus: How Artificial Intelligence, Data Science and Technology Is Used to Fight the Pandemic. Retrieved from https://www.forbes.com/sites/bernardmarr/2020/03 /13/coronavirus-how-artificial-intelligence-datascience-and-technology-is-used-to-fight-thepandemic/\#2eecd0565f5f.
32. https://nextstrain.org/ncov/global

33. Precision Vax LLC. Robert Carlson. INO4800 DNA Coronavirus Vaccine. MAY 2020

34. RAJU MUKHERJEE. April 2020. Global efforts on vaccines for COVID-19: Since, sooner or later, we all will catch the coronavirus.

35. Rapid development of a synthetic DNA vaccine for covid 19. 10.21203/rs.3.rs-16261/v1

36. Milken Institute Website.

37. Pfizer and BioNTech Dose First Participants in the U.S. as Part of Global COVID-19 mRNA Vaccine Development Program. May. 2020. Pfizer.com.

38. Moderna gets FDA 'fast-track' designation for its COVID-19 vaccine 'mRNA-1273' timesnownews.com. MAY 2020.

39. Sinopharm Group (Wuhan Institute of Biological Products) and Chinese Academy of Sciences (Wuhan Institute of Virology). (2020, May 17). Retrieved from https://www.genengnews.com/.

40. Sinopharm Group (China National Biotech Group, Beijing Institute of Biological Products) and Chinese Center for Disease Control and Prevention. (2020, May 18). Retrieved from https://www.genengnews.com/.

41. Nascimento IP, Leite LC. Recombinant vaccines and the development of new vaccine strategies. Braz J Med Biol Res. 2012;45(12):11021111. doi:10.1590/s0100-879x2012007500142.

42. CanSino Biologics. (2020, May 18). Retrieved from https://www.genengnews.com/covid-19candidates/cansino-biologics/

43. https://www.who.int/blueprint/prioritydiseases/keyaction/Table_of_therapeutics_Appendix_1702202 $0 . p d f$ ?ua $=1$ 
44. Clark D Russell, Jonathan E Millar, J Kenneth Baillie, Clinical evidence does not support corticosteroid treatment for 2019-nCoV lung injury.The Lancet. Volume 395, Issue 10223. 2020.Pages 473-475. ISSN 0140-6736. https://doi.org/10.1016/S0140-6736(20)30317-2

45. Chroboczek, Tomasz, et al. "Beneficial effect of corticosteroids in severe COVID-19 pneumonia: a propensity score matching analysis." medRxiv (2020).

46. Sheahan, T.P., Sims, A.C., Leist, S.R. et al. Comparative therapeutic efficacy of remdesivir and combination lopinavir, ritonavir, and interferon beta against MERS-CoV. Nat Commun 11, 222 (2020). https://doi.org/10.1038/s41467-019-13940-6

47. Hsu, Chen-Yang, et al. "Efficacy of remdesivir in COVID-19 patients with a simulated two-arm controlled study." medRxiv (2020).

48. Furuta, Yousuke, et al. "Favipiravir (T-705), a novel viral RNA polymerase inhibitor." Antiviral research 100.2 (2013): 446-454.

49. clincialtrials.gov

(Identifier:NCT04264533)

50. Aranow C. Vitamin $\mathrm{D}$ and the immune system. J Investig Med. 2011;59(6):881-886. doi:10.2310/JIM.0b013e31821b8755

51. C-reactive protein, Retrieved from https://en.wikipedia.org/wiki/C-reactive_protein

52. Daneshkhah, A., Agrawal, V., Eshein, A., Subramanian, H., Roy, H. K., \& Backman, V. (2020, May 18). The Possible Role of Vitamin D in Suppressing Cytokine Storm and Associated Mortality in COVID-19 Patients. Retrieved from https://www.medrxiv.org/content/10.1101/2020.04 $.08 .20058578 \mathrm{v} 4$

53. Carlucci, Philip, et al. "Hydroxychloroquine and azithromycin plus zinc vs hydroxychloroquine and azithromycin alone: outcomes in hospitalized COVID-19 patients." medRxiv (2020). 